Original Research Article

\title{
Alterations in aminergic system of rat brain by the opioid analgesic tramadol in the absence of pain-induction
}

\author{
Sahitya C. Panadanabiona*
}

Department of Biology, Arkansas Biosciences Institute, Jonesboro, Arkansas, USA

Received: 02 October 2017

Revised: 28 October 2017

Accepted: 11 November 2017

*Correspondence to:

Dr. Sahitya C. Panadanabiona, Email: drpandana@gmail.com

Copyright: (c) the author(s), publisher and licensee Medip Academy. This is an openaccess article distributed under the terms of the Creative Commons Attribution NonCommercial License, which permits unrestricted noncommercial use, distribution, and reproduction in any medium, provided the original work is properly cited.

\begin{abstract}
Background: Tramadol is an opioid analgesic used for treating moderate to severe pain. No research is available on pharmacology of tramadol without induction of pain. This study examines the effect of administration of tramadol on the levels of biogenic amines and their metabolites in the brain areas of male adult Wistar rats, without inducing pain.

Methods: Tramadol was injected subcutaneously at 0, 24, and 48 hours, and changes in the levels of epinephrine (EP), norepinephrine (NE), dopamine (DA) and serotonin (5-HT), 5-hydroxyindoleacetic acid (HIAA) and homovanillic acid (HVA) were examined in cerebral cortex, cerebellum, pons-medulla, hippocampus and thalamus. The changes were recorded in the select brain areas at 3,6,12, 24 hours after the first injection, as well as at 24 hours after the second and third injections, respectively.

Results: Administration of tramadol at 0 hours elevated the levels of DA, 5-HT and HVA in all brain areas. Changes in levels of EP, NE, and HIAA varied across the four brain areas surveyed. All parameters showed maximal changes at 3 or 6 hours following the first administration at 0 hours. For the second and third doses of tramadol at 24 and 48 hours respectively, the parameters showed variations at 48 and 72 hours that generally fluctuated around the control.

Conclusions: The results indicate differential tissue responses to administered tramadol in different areas of the brain. The results suggest that the alterations in biogenic amines for the administration of tramadol are similar under both pain and no-pain conditions.
\end{abstract}

Keywords: Biogenic amines, Non-nociception, Rat brain areas, Tramadol

\section{INTRODUCTION}

Different neurotransmitter systems contribute to the modulation of pain perception. The interaction of narcotic analgesics with central and peripheral transmitter systems is presumably related to the development of the wellknown central effects such as analgesia. ${ }^{1,2}$ Opioids constitute one of the largest, most widely used and most effective classes of drugs for the treatment of moderate to severe pain., 3 The analgesic effects are particularly prominent in painful inflammatory conditions. ${ }^{5,6}$ Numerous studies have demonstrated that many experimental pain models involve analgesic assays. ${ }^{7}$
Non-steroid anti-inflammatory drugs (NSAIDs) and paracetamol are suggested to exert their analgesic effects through direct or indirect activation of the serotonergic system. ${ }^{8}$ The regulation of 5-HT release in the dorsal raphe nucleus of the rat brain during the development of opioid tolerance and dependence was examined by Tao et al. ${ }^{9}$

Tramadol is an opioid used as an analgesic for treating moderate to severe pain. ${ }^{10}$ It is believed to work through modulation of the GABAergic, noradrenergic and serotonergic systems. Tramadol and its metabolite M1 have been found to bind to $\mu$-opioid receptors, thus exerting its effect on GABAergic transmission, and to 
inhibit reuptake of 5-HT and noradrenalin. ${ }^{11}$ The serotonergic modulating properties of tramadol mean that it has the potential to interact with other serotonergic agents. There is an increased risk of serotonin syndrome when tramadol is taken in combination with reuptake inhibitors, agents that potentiate the effect of 5-HT or 5HT agonists. ${ }^{12}$ Research on aminergic system with reference to the effects of tramadol has been concentrated on its antidepressant effects with reference to the uptake and release of NE, 5-HT, DA etc., besides the dependence potential and metabolis m. ${ }^{13-17}$

Some controversy exists regarding the dependence liability of tramadol, assessed the drug dependence and abuse liability of tramadol and concluded that tramadol produced high abuse potential among opiate addicts..$^{18}$ Contrary to this, Preston et al, found that although tramadol 300mg was identified as an opiate, it did not produce many morphine-like effects, and that tramadol has a low abuse potentialby the parenteral route. ${ }^{19}$

Analgesia given before a nociceptive stimulus begins is generally suggested to be more effective than the same dose given after the stimulus. It has been suggested that the same dose of an analgesic given by the same route may be more effective if given before surgery. However, the animal models do not provide clear indications of a timeframe for the analgesic effect, or the underlying mechanism, or to which pain models these findings may apply. Trials of adequate design and size are required to assess the role of local anesthetics and opioids in preemptive analgesia. The review of McQuay provides information on pre-emptive analgesia in clinical studies..$^{20}$

Literature on the biogenic amines and analgesic drugs reveals that the research has been more focused on the effects of morphine, and the other opioid and non-opioid analgesics have not received much attention. Keeping this in view, the present study was undertaken to examine the effects of the opioid drug tramadol. The studies with tramadol and biogenic amines hitherto have addressed the anti-nociceptive action of tramadol and its effect on transmitter release and uptake. ${ }^{21-23}$ In the light of literature on the effects of opioid analgesics on the levels of biogenic amines under pain conditions, the present study was taken up to examine the effect of administration of tramadol without induction of pain on the levels of biogenic amines and their metabolites in different brain areas of the rat at different times following drug administration, to see if the effects would be the same under pain conditions and nonpain conditions. ${ }^{18}$

\section{METHODS}

\section{Experimental animals}

Male adult Wistar rats weighing $150 \pm 20$ grams were purchased from the Indian Institute of Science, Bangalore, India, and maintained in polypropylene cages under laboratory conditions of $28 \pm 2^{\circ} \mathrm{C}$ temperature, LD 12:12 photoperiod, and $75 \%$ relative humidity. The rats were given standard pellet diet and water ad libitum. They rats were maintained according to the ethical guidelines for animal protection and welfare bearing the CPCSEA regulation and resolution.

\section{Selection of the drug}

Tramadol was obtained as a commercial grade chemical from Apollo Pharmacy, Hyderabad, India. It is marketed as a racemic mixture of the $(1 \mathrm{R}, 2 \mathrm{R})$ - and $(1 \mathrm{~S}, 2 \mathrm{~S})$ enantiomers with a weak affinity for the $\mu$-opioid receptor. ${ }^{24}$ The $(1 \mathrm{R}, 2 \mathrm{R})-(+)$-enantiomer is approximately four times more potent than the (1S, 2S)-(-)-enantiomer in terms of $\mu$-opioid receptor affinity and 5-HT reuptake, whereas the $(1 \mathrm{~S}, 2 \mathrm{~S})-(-)$-enantiomer is responsible for noradrenalin reuptake effects. ${ }^{25}$ These actions appear to produce a synergistic analgesic effect, with (1R, 2R)-(+)tramadol exhibiting 10-fold higher analgesic activity than (1S, 2S)-(-)-tramadol. ${ }^{26}$

\section{Dosage and administration of tramadol}

After acclimation, the rats were divided into separate groups depending on the dosage and time for sacrificing them. Six groups, with six rats in each group, were housed in separate cages. All the rats were injected with tramadol subcutaneously at 0,24 , and 48 hours. The time periods chosen for assaying the biogenic amines following tramadol administration were $3,6,12,24,48$, and 72 hours.

All doses were given between 9 and 10 AM to ward off interference of diurnal rhythms, if any, in activity. Tramadol was administered according to ED50 value obtained in rats at $31 \mathrm{mg} / \mathrm{kg}$ in hot plate test. ${ }^{27}$ The control groups of six rats received physiological saline instead of tramadol dose. Single controls were used for each brain area for comparison with all the experimental groups of all the time periods.

\section{Isolation of tissues}

The rats were sacrificed at the chosen times mentioned above. The brain was isolated immediately and placed on a chilled glass plate. The brain areas, namely cerebral cortex (CC), cerebellum (CB), pons-medulla (PM), hippocampus (HI) and thalamus $(\mathrm{TH})$, were separated and isolation of synaptosomes was done using conventional methods. ${ }^{28-30}$

\section{Estimation of biogenic amines}

Extraction and estimation of catecholamines and serotonin were carried out according to the method of Kari et al, 5Hydroxyindoleacetic acid and homovanillic acid were estimated as per Anden et al, and Haubrich and Denzer. ${ }^{31-}$ ${ }^{33}$ The amine content of each tis sue sample was calculated by the modified method of Ansell and Beeson, as given by Kari. ${ }^{31,34}$ 


\section{Statistical analysis}

All the assays were carried out with six separate replicates (6 rats) from each group. The mean and standard deviation (SD) were worked out using INSTAT statistical software. Analysis of Variance (ANOVA) was done with SPSS statistical software on IBM compatible personal computer. Differences between control and experimental values were considered statistically significant if $\mathrm{P}$ values are less than 0.05 .

\section{RESULTS}

\section{Norepinephrine}

In control rats, highest level of $\mathrm{NE}$ in the brain was recorded in CC, and lowest level in CB. Following the administration of initial dose of tramadol at 0 hours, while $\mathrm{CC}$ and $\mathrm{CB}$ recorded the highest increase, $\mathrm{PM}, \mathrm{HI}$ and $\mathrm{TH}$ recorded the highest decrease in NE content, all at 3 hours. Following this, the NE levels reverted back towards the respective controllevels at 6,12 and 24 hours. At 24 hours, the NE content in all areas reached more or less the respective control levels.
Following the second and third administrations of tramadol at 24 and 48 hours respectively, the NE levels in different brain areas at 48 and 72 hours respectively did not show statistically significant deviations (Table 1).

\section{Epinephrine}

In control rats, highest level of EP was recorded in the CC, and lowest content in CB. The first dose of tramadol at 0 hours caused differential effects on EP levels in different areas of the brain, with maximal elevation in $\mathrm{CC}$ at 3 hours, $\mathrm{CB}$ and PM at 6 hours; and maximal decrease in $\mathrm{HI}$ at 3 hours and in TH at 6 hours. Following maximal increase or decrease at 3 or 6 hours in different brain areas after tramadol injection, the EP content showed a reversal towards the respective controls during succeeding time periods. At 24 hours after the initial tramadol administration, the EP content in all areas of the brain recovered more or less to the control levels. The second and third injections of tramadol at 24 and 48 hours respectively caused minor positive deviations in EP levels in different brain areas at 48 and 72 hours respectively, which were statistically not significant (Table 2).

Table 1: Changes in the norepinephrine (NE) content in different brain regions of rats at different time periods after administration of acute and sub-chronic dose of tramadol at $0,24,48$ and 72 hours.

\begin{tabular}{|c|c|c|c|c|c|c|c|c|}
\hline Brain Area & Indices & Control & 3 hrs & $6 \mathrm{hrs}$ & $12 \mathrm{hrs}$ & $24 \mathrm{hrs}$ & $48 \mathrm{hrs}$ & $72 \mathrm{hrs}$ \\
\hline \multirow{3}{*}{ Cortex } & Mean & 4.63 & 5.97 & 5.76 & 5.08 & 4.45 & 4.87 & 4.75 \\
\hline & $\mathrm{SD}( \pm)$ & 0.32 & 0.46 & 0.46 & 0.45 & 0.34 & 0.40 & 0.38 \\
\hline & $\%$ Change & & +28.94 & +24.40 & $+9.72 *$ & $-3.89 *$ & $+5.18^{*}$ & $+2.59 *$ \\
\hline \multirow{3}{*}{ Cerebellum } & Mean & 1.29 & 1.89 & 1.82 & 1.55 & 1.39 & 1.45 & 1.49 \\
\hline & $\mathrm{SD}( \pm)$ & 0.14 & 0.21 & 0.29 & 0.21 & 0.24 & 0.18 & 0.23 \\
\hline & $\%$ Change & & +46.51 & +41.08 & +20.15 & $+7.75^{*}$ & $+12.40^{*}$ & $+15.50^{*}$ \\
\hline \multirow{3}{*}{ Pons-Medulla } & Mean & 1.88 & 1.29 & 1.39 & 1.44 & 1.63 & 1.58 & 1.61 \\
\hline & $\mathrm{SD}( \pm)$ & 0.37 & 0.30 & 0.31 & 0.34 & 0.26 & 0.24 & 0.32 \\
\hline & $\%$ Change & & -31.38 & -26.06 & -23.41 & $-13.30^{*}$ & $-15.96^{*}$ & $-14.37 *$ \\
\hline \multirow{3}{*}{ Hippocampus } & Mean & 1.57 & 1.41 & 1.42 & 1.61 & 1.67 & 1.71 & 1.65 \\
\hline & $\mathrm{SD}( \pm)$ & 0.19 & 0.15 & 0.17 & 0.20 & 0.21 & 0.23 & 0.18 \\
\hline & $\%$ Change & & $-10.19 *$ & $-9.56^{*}$ & $+2.55^{*}$ & $+6.37^{*}$ & $+8.91 *$ & $+5.09^{*}$ \\
\hline \multirow{3}{*}{ Thalamus } & Mean & 1.31 & 0.99 & 1.03 & 1.15 & 1.35 & 1.37 & 1.39 \\
\hline & $\mathrm{SD}( \pm)$ & 0.09 & 0.09 & 0.08 & 0.14 & 0.09 & 0.11 & 0.13 \\
\hline & $\%$ Change & & -24.43 & -21.37 & -12.21 & $+3.05^{*}$ & $+4.58^{*}$ & $+6.11^{*}$ \\
\hline
\end{tabular}

Each value, expressed in $\mu \mathrm{g}$ of NE/g wet wt of tissue, is the mean \pm standard deviation (S.D.) of observations from six separate experiments. Values are significant at least at $\mathrm{P}<0.05$ in SNK test. * Not significant

\section{Dopamine}

In control rats, the highest level of dopamine was recorded in $\mathrm{HI}$ and the lowest content was recorded in CB. Following tramadol administration at 0 hours, the DA levels showed an increase in all areas of the brain, with highest increases in $\mathrm{CC}$ and $\mathrm{CB}$ at 6 hours, $\mathrm{PM}, \mathrm{HI}$ and $\mathrm{TH}$ at 3 hours. As in the case of NE and EP, the DA content in all the areas reverted towards the respective controls during the succeeding time periods, and reached more or less the control levels at 24 hours after the first administration of tramadol.

On administering tramadol for the second and third times at 24 and 48 hours respectively, the DA levels showed only slight positive deviations in different brain areas at 48 and 72 hours, which were statistically significant in CC and not significant in the rest of the brain areas (Table 3 ). 
Table 2: Changes in the epinephrine (EP) content in different brain regions of rats at different time periods after administration of acute and sub-chronic dose of tramadol at 0, 24, 48 and 72 hours.

\begin{tabular}{|c|c|c|c|c|c|c|c|c|}
\hline Brain Area & Indices & Control & 3 hrs & $6 \mathrm{hrs}$ & $12 \mathrm{hrs}$ & 24 hrs & $48 \mathrm{hrs}$ & 72 hrs \\
\hline \multirow{3}{*}{ Cortex } & Mean & 2.25 & 2.75 & 2.70 & 2.53 & 2.31 & 2.35 & 2.39 \\
\hline & $\mathrm{SD}( \pm)$ & 0.16 & 0.17 & 0.17 & 0.11 & 0.11 & 0.14 & 0.16 \\
\hline & $\%$ Change & & +22.22 & +20.00 & +12.44 & $+2.67 *$ & $+4.44^{*}$ & $+6.22 *$ \\
\hline \multirow{3}{*}{ Cerebellum } & Mean & 0.97 & 1.22 & 1.24 & 1.15 & 1.03 & 1.05 & 1.07 \\
\hline & $\mathrm{SD}( \pm)$ & 0.10 & 0.08 & 0.07 & 0.11 & 0.12 & 0.13 & 0.14 \\
\hline & $\%$ Change & & +25.77 & +27.83 & +18.55 & $+6.18^{*}$ & $+8.25^{*}$ & $+10.30 *$ \\
\hline \multirow{3}{*}{$\begin{array}{l}\text { Pons- } \\
\text { Medulla }\end{array}$} & Mean & 1.01 & 1.31 & 1.35 & 1.12 & 1.07 & 1.09 & 1.11 \\
\hline & $\mathrm{SD}( \pm)$ & 0.05 & 0.09 & 0.13 & 0.09 & 0.08 & 0.11 & 0.12 \\
\hline & $\%$ Change & & +29.70 & +33.66 & +10.89 & $+5.94 *$ & $+7.92 *$ & $+9.90^{*}$ \\
\hline \multirow{3}{*}{ Hippocampus } & Mean & 1.12 & 0.98 & 1.00 & 1.04 & 1.09 & 1.15 & 1.18 \\
\hline & $\mathrm{SD}( \pm)$ & 0.07 & 0.08 & 0.06 & 0.08 & 0.09 & 0.11 & 0.12 \\
\hline & $\%$ Change & & -12.50 & -10.72 & $-7.14^{*}$ & $-2.68^{*}$ & $+2.68 *$ & $+5.36^{*}$ \\
\hline \multirow{3}{*}{ Thalamus } & Mean & 1.00 & 0.89 & 0.82 & 1.11 & 1.02 & 1.04 & 1.06 \\
\hline & $\mathrm{SD}( \pm)$ & 0.06 & 0.07 & 0.09 & 0.08 & 0.09 & 0.10 & 0.11 \\
\hline & $\%$ Change & & -11.00 & -18.00 & +11.00 & $+2.00 *$ & $+4.00 *$ & $+6.00 *$ \\
\hline
\end{tabular}

Each value is expressed in $\mu \mathrm{g}$ of $\mathrm{EP} / \mathrm{g}$ wet wt of tissue. Rest of the note is the same as in Table 1

Table 3: Changes in the dopamine (DA) content in different brain regions of rats at different time periods after administration of acute and sub-chronic dose of tramadol at $0,24,48$ and 72 hours.

\begin{tabular}{|c|c|c|c|c|c|c|c|c|}
\hline Brain Area & Indices & Control & $3 \mathrm{hrs}$ & $6 \mathrm{hrs}$ & $12 \mathrm{hrs}$ & 24 hrs & 48 hrs & $72 \mathrm{hrs}$ \\
\hline \multirow{3}{*}{ Cortex } & Mean & 2.82 & 3.67 & 3.73 & 3.55 & 3.11 & 3.19 & 3.25 \\
\hline & $\mathrm{SD}( \pm)$ & 0.27 & 0.21 & 0.26 & 0.21 & 0.35 & 0.31 & 0.33 \\
\hline & $\%$ Change & & +30.14 & +32.27 & +25.88 & $+10.28^{*}$ & +13.12 & +15.25 \\
\hline \multirow{3}{*}{ Cerebellum } & Mean & 1.35 & 1.65 & 1.68 & 1.52 & 1.29 & 1.37 & 1.41 \\
\hline & $\mathrm{SD}( \pm)$ & 0.19 & 0.14 & 0.17 & 0.13 & 0.17 & 0.18 & 0.21 \\
\hline & $\%$ Change & & +22.22 & +24.44 & +12.59 & $-4.45^{*}$ & $+1.48^{*}$ & $+4.44 *$ \\
\hline \multirow{3}{*}{ Pons-Medulla } & Mean & 3.49 & 4.64 & 4.45 & 3.97 & 3.76 & 3.81 & 3,86 \\
\hline & $\mathrm{SD}( \pm)$ & 0.26 & 0.30 & 0.28 & 0.28 & 0.29 & 0.31 & 0.33 \\
\hline & $\%$ Change & & +32.95 & +27.50 & +13.75 & $+7.74 *$ & $+9.17^{*}$ & $+10.60 *$ \\
\hline \multirow{3}{*}{ Hippocampus } & Mean & 5.83 & 7.12 & 6.90 & 6.44 & 6.28 & 6.31 & 6.39 \\
\hline & $\mathrm{SD}( \pm)$ & 0.34 & 0.30 & 0.30 & 0.26 & 0.30 & 0.32 & 0.33 \\
\hline & $\%$ Change & & +22.13 & +18.35 & +10.46 & $+7.72 *$ & $+8.23^{*}$ & $+9.61 *$ \\
\hline \multirow{3}{*}{ Thalamus } & Mean & 1.40 & 1.92 & 1.84 & 1.64 & 1.48 & 1.51 & 1.53 \\
\hline & $\mathrm{SD}( \pm)$ & 0.18 & 0.19 & 0.14 & 0.14 & 0.15 & 0.16 & 0.17 \\
\hline & $\%$ Change & & +37.14 & +31.43 & +17.14 & $+5.71 *$ & $+7.86^{*}$ & $+9.29 *$ \\
\hline
\end{tabular}

Each value, expressed in $\mu \mathrm{g}$ of DA/g wet wt of tissue. Rest of the note is the same as in Table 1

\section{5-Hydroxytryptamine}

In control rats, the highest 5-HT content was found in PM, and the lowest level was recorded in HI. The trend of changes in 5-HT content was similar to that in DA.

Following injection of the initial dose of tramadol, the 5HT content in all areas of the brain recorded an increase, with maximal elevation occurring at 3 hours in all the areas after injection of the drug. Following this, the 5-HT content showed a recovery towards the controls during the succeeding periods. At 24 hours following tramadol administration the 5-HT content recovered more or less to the control levels.
Following the second and third administrations of tramadol at 24 and 48 hours respectively, the 5-HT levels showed non-significant positive deviations in different brain areas at 48 and 72 hours respectively (Table 4 ).

\section{5-Hydroxyindoleacetic acid}

In controls, the content of HIAA was found to be highest in $\mathrm{CC}$ and lowest in $\mathrm{TH}$.

Upon the initial tramadol dosing, the HIAA content showed a decrease in different areas of the brain, with the exception of $\mathrm{CB}$ in which the content showed an increase. The maximal decreases recorded were $31.67 \%$ in $\mathrm{CC}$, 37.79 in $\mathrm{PM}, 19.33 \%$ in $\mathrm{HI}$, and $15.75 \%$ in $\mathrm{TH}$, all at 3 
hours following the first administration. CB recorded the highest increase of $27.48 \%$ at 6 hours following the initial administration. Following this, the HIAA content showed recovery towards the control levels, and by 24 hours the content returned more or less to the respective control levels. The second and third administrations of tramadol at 24 and 48 hours respectively caused slight and nonsignificant deviations in HIAA levels (Table 5).

Table 4: Changes in the 5-hydroxytryptamine (5-HT) content in different brain regions of rats at different time periods after administration of acute and sub-chronic dose of tramadol at $0,24,48$ and 72 hours.

\begin{tabular}{|c|c|c|c|c|c|c|c|c|}
\hline Brain Area & Indices & Control & $3 \mathrm{hrs}$ & $6 \mathrm{hrs}$ & $12 \mathrm{hrs}$ & $24 \mathrm{hrs}$ & $48 \mathrm{hrs}$ & $72 \mathrm{hrs}$ \\
\hline \multirow{3}{*}{ Cortex } & Mean & 2.27 & 2.86 & 2.73 & 2.22 & 2.16 & 2.32 & 2.38 \\
\hline & $\mathrm{SD}( \pm)$ & 0.31 & 0.25 & 0.18 & 0.26 & 0.27 & 0.28 & 0.33 \\
\hline & $\%$ Change & & +25.99 & +20.26 & $-2.20 *$ & $-4.85^{*}$ & $+2.20 *$ & $+4.84 *$ \\
\hline \multirow{3}{*}{ Cerebellum } & Mean & 1.71 & 1.99 & 1.92 & 1.83 & 1.75 & 1.78 & 1.81 \\
\hline & $\mathrm{SD}( \pm)$ & 0.23 & 0.14 & 0.09 & 0.18 & 0.15 & 0.16 & 0.17 \\
\hline & $\%$ Change & & +16.37 & +12.28 & $+7.02 *$ & $+2.34^{*}$ & $+4.09 *$ & $+5.85 *$ \\
\hline \multirow{3}{*}{ Pons-Medulla } & Mean & 3.93 & 4.84 & 4.71 & 4.29 & 4.17 & 4.23 & 4.27 \\
\hline & $\mathrm{SD}( \pm)$ & 0.21 & 0.16 & 0.12 & 0.24 & 0.22 & 0.23 & 0.25 \\
\hline & $\%$ Change & & +23.15 & +19.84 & $+9.16^{*}$ & $+6.11^{*}$ & $+7.63^{*}$ & $+8.65^{*}$ \\
\hline \multirow{3}{*}{ Hippocampus } & Mean & 0.42 & 0.57 & 0.52 & 0.49 & 0.47 & 0.45 & 0.46 \\
\hline & $\mathrm{SD}( \pm)$ & 0.06 & 0.09 & 0.07 & 0.06 & 0.10 & 0.08 & 0.09 \\
\hline & $\%$ Change & & +35.71 & +23.8 & +16.66 & $+11.90^{*}$ & $+7.14^{*}$ & $+9.52 *$ \\
\hline \multirow{3}{*}{ Thalamus } & Mean & 1.19 & 1.57 & 1.46 & 1.30 & 1.23 & 1.25 & 1.27 \\
\hline & $\mathrm{SD}( \pm)$ & 0.12 & 0.15 & 0.13 & 0.13 & 0.08 & 0.09 & 0.11 \\
\hline & $\%$ Change & & +31.93 & +22.69 & $+9.24^{*}$ & $+3.36^{*}$ & $+5.04^{*}$ & $+6.72 *$ \\
\hline
\end{tabular}

Each value, expressed in $\mu \mathrm{g}$ of 5-HT/g wet wt of tissue. Rest of the note is the same as in Table 1

Table 5: Changes in the 5-hydroxy indole acetic acid (5-HIAA) content in different brain regions of rats at different time periods after administration of acute and sub-chronic dose of tramadol at $0,24,48$ and 72 hours.

\begin{tabular}{|c|c|c|c|c|c|c|c|c|}
\hline Brain Area & Indices & Control & $3 \mathrm{hrs}$ & $6 \mathrm{hrs}$ & $12 \mathrm{hrs}$ & $24 \mathrm{hrs}$ & $48 \mathrm{hrs}$ & $72 \mathrm{hrs}$ \\
\hline \multirow{3}{*}{ Cortex } & Mean & 1.80 & 1.23 & 1.29 & 1.52 & 1.89 & 1.71 & 1.68 \\
\hline & $\mathrm{SD}( \pm)$ & 0.14 & 0.17 & 0.19 & 0.21 & 0.15 & 0.16 & 0.18 \\
\hline & $\%$ Change & & -31.67 & -28.33 & -15.56 & $+5.00 *$ & $-5.00 *$ & $-6.67 *$ \\
\hline \multirow{3}{*}{ Cerebellum } & Mean & 1.31 & 1.63 & 1.67 & 1.33 & 1.28 & 1.34 & 1.36 \\
\hline & $\mathrm{SD}( \pm)$ & 0.13 & 0.14 & 0.16 & 0.15 & 0.16 & 0.17 & 0.18 \\
\hline & $\%$ Change & & +24.43 & +27.48 & $+1.53^{*}$ & $-2.80 *$ & $+2.29 *$ & $+3.82^{*}$ \\
\hline \multirow{3}{*}{ Pons-Medulla } & Mean & 1.72 & 1.07 & 1.32 & 1.54 & 1.88 & 1.66 & 1.60 \\
\hline & $\mathrm{SD}( \pm)$ & 0.19 & 0.23 & 0.18 & 0.20 & 0.21 & 0.19 & 0.22 \\
\hline & $\%$ Change & & -37.79 & -23.26 & -10.47 & $+9.30^{*}$ & $-3.49 *$ & $-6.98 *$ \\
\hline \multirow{3}{*}{ Hippocampus } & Mean & 1.50 & 1.21 & 1.26 & 1.39 & 1.46 & 1.44 & 1.42 \\
\hline & $\mathrm{SD}( \pm)$ & 0.13 & 0.14 & 0.15 & 0.13 & 0.16 & 0.17 & 0.18 \\
\hline & $\%$ Change & & -19.33 & -16.00 & $-7.33^{*}$ & $-2.67 *$ & $-4.00 *$ & $-5.33^{*}$ \\
\hline \multirow{3}{*}{ Thalamus } & Mean & 1.27 & 1.07 & 1.14 & 1.16 & 1.25 & 1.23 & 1.20 \\
\hline & $\mathrm{SD}( \pm)$ & 0.09 & 0.11 & 0.11 & 0.12 & 0.09 & 0.10 & 0.13 \\
\hline & $\%$ Change & & -15.75 & -10.24 & $-8.66^{*}$ & $-1.58 *$ & $-3.15^{*}$ & $-5.51 *$ \\
\hline
\end{tabular}

Each value, expressed in $\mu \mathrm{g}$ of 5-HIAA/g wet wt of tissue. Rest of the note is the same as in Table 1

\section{Homovanillic acid}

In control rats, the HVA content was highest in $\mathrm{TH}$ and lowest in PM. Following the initial administration of tramadol at 0 hours, the HVA content showed an increase in all areas of the brain by 3 to 6 hours. Maximal increases were recorded in CC (37.5\%) and PM (40.9\%) at 3 hours; and in $\mathrm{CB}(25 \%)$, $\mathrm{HI}(26.51 \%)$ and $\mathrm{TH}(43.33 \%)$ at 6 hours following the first administration of tramadol. Following this, the HVA content started to revert back, and by 24 hours the HVA content reached more less the respective control levels in different brain areas. On administering tramadol for the second and third times at 24 and 48 hours respectively, the HVA levels showed non-significant deviations in different brain areas at 48 and 72 hours respectively (Table 6). 
Table 6: Changes in the homovanillic acid (HVA) content in different brain regions of rats at different time periods after administration acute and sub-chronic dose of tramadol at $0,24,48$ and 72 hours.

\begin{tabular}{|c|c|c|c|c|c|c|c|c|}
\hline Brain Area & Indices & Control & $3 \mathrm{hrs}$ & $6 \mathrm{hrs}$ & $12 \mathrm{hrs}$ & $24 \mathrm{hrs}$ & $48 \mathrm{hrs}$ & $72 \mathrm{hrs}$ \\
\hline \multirow{3}{*}{ Cortex } & Mean & 0.40 & 0.55 & 0.49 & 0.43 & 0.37 & 0.38 & 0.41 \\
\hline & $\mathrm{SD}( \pm)$ & 0.08 & 0.09 & 0.08 & 0.09 & 0.09 & 0.10 & 0.11 \\
\hline & $\%$ Change & & +37.50 & +22.50 & $+7.50 *$ & $-7.50 *$ & $-5.00 *$ & $+2.50 *$ \\
\hline \multirow{3}{*}{ Cerebellum } & Mean & 0.68 & 0.77 & 0.85 & 0.75 & 0.65 & 0.66 & 0.64 \\
\hline & $\mathrm{SD}( \pm)$ & 0.05 & 0.08 & 0.09 & 0.07 & 0.08 & 0.09 & 0.10 \\
\hline & $\%$ Change & & +13.23 & +25.00 & $+10.29 *$ & $-4.41 *$ & $-2.94 *$ & $-5.88^{*}$ \\
\hline \multirow{3}{*}{ Pons-Medulla } & Mean & 0.22 & 0.31 & 0.28 & 0.25 & 0.24 & 0.23 & 0.25 \\
\hline & $\mathrm{SD}( \pm)$ & 0.04 & 0.05 & 0.05 & 0.07 & 0.08 & 0.08 & 0.09 \\
\hline & $\%$ Change & & +40.90 & +27.27 & $+13.64 *$ & $+9.09 *$ & $+4.54^{*}$ & $+13.64^{*}$ \\
\hline \multirow{3}{*}{ Hippocampus } & Mean & 0.83 & 0.98 & 1.05 & 0.91 & 0.79 & 0.80 & 0.81 \\
\hline & $\mathrm{SD}( \pm)$ & 0.08 & 0.06 & 0.07 & 0.05 & 0.09 & 0.08 & \\
\hline & $\%$ Change & & +18.07 & +26.51 & $+9.64 *$ & $-4.82 *$ & $-3.61^{*}$ & $0.102 .41 *$ \\
\hline \multirow{3}{*}{ Thalamus } & Mean & 0.90 & 1.19 & 1.29 & 1.00 & 0.83 & 0.87 & 0.91 \\
\hline & $\mathrm{SD}( \pm)$ & 0.08 & 0.07 & 0.11 & 0.08 & 0.09 & 0.07 & 0.11 \\
\hline & $\%$ Change & & +32.22 & +43.33 & +11.11 & $-7.78 *$ & $-3.33^{*}$ & $+1.11 *$ \\
\hline
\end{tabular}

Each value, expressed in $\mu \mathrm{g}$ of HVA /g wet wt of tissue. Rest of the note is the same as in Table 1

\section{DISCUSSION}

The effective dose of tramadol of $31 \mathrm{mg} / \mathrm{kg}$ administered subcutaneously in the present study seems to have half-life similar to that under oral adminis tration reported by Dayer et $\mathrm{al}^{35}$ Thus, the effect of subcutaneous dose $(31 \mathrm{mg} / \mathrm{kg}$ ) used in the present study appears to be matching with that of the single oral dose. In the light of this, the maximal positive or negative peaks at 3 or 6 hours observed for the parameters related to biogenic amines examined in this study, and the return of the parameters to control levels by about 24 hours after the adminis tration of tramadol appear reasonable. Again, tramadol seems to cause the observed changes in the presence of pain and during pre-emptive analgesia as reported in literature, as well as during noninduction of pain as in the present study. The observed changes in parameters related to biogenic amines are presumably among the general contrivances for analgesic effects.

The influence of tramadol on biogenic amine neurotransmitters was examined in the rat brain by Frink et al. $^{36}$ In their study, ex vivo neurotransmitter determinations showed that tramadol (46.4mg/kg,i.p.) elevated the DA metabolites 3,4-dihydroxyphenylacetic acid (DOPAC) and homovanillic acid (HVA) and enhanced DA release in definite brain areas. The active enantiomer of the racemic tramadol, the (+)-enantiomer, significantly enhanced the turnover rate of DA. Tramadol reduced 5-HT utilization in the brain. Their results further indicated that tramadol enhances DA turnover via an opioid mechanism. The interaction of tramadol with the noradrenergic and serotonergic neurotransmission closely resembled that of NA and 5-HT uptake inhibitors. Our findings are in general agreement with the observations of Frink et al. ${ }^{36}$
The present study focused on changes in the aminergic system under tramadol analgesia without induction of pain. The biogenic amines and the metabolites showed differential levels in different brain areas following tramadol administration (Tables 1 to Table 6). Tramadol dose-dependently increased extracellular serotonin and NE levels in the ventral hippocampus of freely moving rats, and was found to affect the uptake and release of NE and DA in hypothalamus. ${ }^{12,37}$ NEappears to be more active in spinal cord, lower brainstem and $\mathrm{CB}$, whereas $\mathrm{DA}$ is often the more effective agent in various parts of the forebrain. DA is considered in great detail when dealing with areas such as striatum, where it is present in particularly large amounts, and is believed to have an important transmitter role. ${ }^{38}$

$\mathrm{CC}$ has been reported to play a key role in processing nociceptive information. Clinical and experimental data indicate that $\mathrm{CC}$ is important for functioning of the endogenous anti-nociceptive system. ${ }^{39}$ Further, 5-HT2 receptors are predominantly located supraspinally and concentrated in the dorsal raphe nucleus and in the frontal cortex ${ }^{40}$ In the present study, significant increases in all parameters, except HIAA which showed decrease have been noticed in $\mathrm{CC}$.

While 5-HT, DA, and HVA contents recorded increases in all areas of the brain following the initial injection of tramadol, NE, EP, and HIAA showed increase in some areas and decrease in the others. Differential changes in a parameter in different areas of the brain under the same conditions reflect variations in the tissue response from different locations. Some or all of these responses could be part of the analgesic effect of tramadol. It has been stated that successfulclinical use of opioids requires appropriate 
selection of the drug and dose for the given species to avoid undesirable side effects. ${ }^{41}$

It has been reported that opioids or endorphins upon binding with the receptors inhibit the release of excitatory neurotransmitters from the terminals of neurons carrying nociceptive stimuli. By decreasing the dose, excitement can be avoided. Excitement may result indirectly from increased release of $\mathrm{NE}$ and DA. ${ }^{41}$ Centrally, at the level of the mesencephalon and medulla, opioids activate the descending endogenous anti-nociceptive system that modulates nociception in the dorsal horn via release of 5HT and perhaps NE. ${ }^{41}$ The increase in biogenic amines and their metabolites in different areas of the brain after tramadol administration in the present study presumably reflect similar possibilities even under non-nociceptive conditions.

The present investigation recorded an increase in dopamine level in all areas of the brain examined (Table 3). Drugs belonging to different pharmacological classes but sharing the characteristic of being rewarding share the properties of preferentially increasing synaptic dopamine concentrations in the mesolimbic dopaminergic system and of stimulating behavior. The drugs showing these properties include central stimulants (amphetamine and cocaine), opiates (morphine, methadone, and fentanyl), central depressants (ethanol) and cholinergic agonists (nicotine). ${ }^{42-45}$

Tramadol administration significantly increased the 5-HT levels in all areas of the brain examined in the present study (Table 4). At the dose of $10 \mathrm{mg} / \mathrm{kg}$, the NSAID rofecoxib was reported to significantly increase the levels of serotonin in frontal and temporal-parietal cortex 120 min after treatment. ${ }^{46}$ Increase in 5 -HT levels seem to be one of the changes underlying anti-nociception.

Tramadol and its active metabolite inhibit reuptake of norepinephrine and enhance the secretion of serotonin, achieving modulation of pain in the central nervous system. ${ }^{40}$ Tramadol was found to inhibit the reuptake of NE and promote the release of 5-HT. ${ }^{41}$ The contribution of enhanced monoaminergic transmission to the analgesic actions of tramadol is supported by the blocking of antinociceptive effects of intrathecal tramadol, but not those of morphine, by yohimbine and ritanserin. ${ }^{47}$ The synergy of monoaminergic and opioid activity achieves analgesic effects. Results of the present investigation showing increased levels of NE in some areas and those of 5-HT in all areas the brain agree with the above observations.

The present investigation has shown that tramadol steps up the accumulation of biogenic amines and HVA in most of the areas, while it causes a decrease in HIAA in all areas. The fact that the levels of the parameters at 48 and 72 hours were similar to those recorded at 24 hours following tramadol administration drives us to assume that the timecourse of changes would be similar after second and third administrations as observed up to 24 hours for the initial administration. And, the observed quick reversal of the effects of tramadol with time as in the present study presumably indicates a low addiction potential for this drug.

\section{CONCLUSION}

From our study, it could be concluded that the effects of tramadol are essentially same during nociception as well as during non-induction of pain. The differences in the effects of tramadol on the levels of biogenic amines in different areas of the brain may reflect differential tis sue responses. Presumably, non-significant changes in the studied parameters upon repeated administration of tramadol at 24 and 48 hours may reflect adaptive response in the CNS to the additional administrations.

Funding: No funding sources

Conflict of interest: None declared

Ethical approval: The study was approved by the Institutional Ethics Committee

\section{REFERENCES}

1. Fürst S. Transmitters involved in antinociception in the spinal cord. Brain Res Bull. 1999;48(2):129-41.

2. Leknes S, Tracey I. A common neurobiology for pain and pleasure. Nat Rev Neurosci. 2008;9(4):314-20.

3. Gutstein HB, Akil H. Opioid analgesics. In: Goodman and Gilman's The Pharmacological Basis of Therapeutics. New York: McGraw-Hill; 2001:569.

4. Fries DS. Opioid analgesics. In: Foye's Principles of Medicinal Chemistry. Philadelphia: Williams and Wilkins Lippincott; 2002:453.

5. Schäfer M. Peripheral opioid analgesia: from experimental to clinical studies. Current Opinion in Anaesthesiology. 1999;12(1):603-7.

6. Stein C. Opioid receptors on peripheral sensory neurons. In: Immune Mechanisms of Pain and Analgesia. Georgetown: Eurekah.com/Landes Bioscience; 2001:69.

7. Hummel T, Roscher S, Pauli E, Frank M, Liefhold J, Wand F, et al. Assessment of analgesia in man: Tramadol controlled release formula vs tramadol standard formulation. Eur J Clin Pharmacol. 1996;51(1):31-8.

8. Pe'lissier T, Alloui A, Caussade F, Dubray C, Cloarec A, Lavarenne J, et al. Paracetamol exerts a spinal antinociceptive effect involving an indirect interaction with 5-hydroxytryptamine 3 receptors: in vivo and in vitro evidence. J Pharmacol Exp Ther. 1996;278(1):814.

9. Tao R, Ma Z, Auerbach SB. Alteration in regulation of serotonin release in rat dorsal raphe nucleus after prolonged exposure to morphine. J Pharmacol Exp Ther. 1998;286(1):481-8.

10. Kimura M, Obata H, Saito S. Antihypersensitivity effects of tramadol hydrochloride in a rat model of postoperative pain. Anesthesia and Analgesia. 2012;115(2):443-9. 
11. Munro G, Baek CAE, Erichsen HK, Nielsen AN, Nielsen EØ, Scheel-Kruger $J$, et al. The novel compound ( \pm )-1-[10-((E)-3-Phenyl-allyl)-3,10-dia zabicyclo[4.3.1]dec-3-yl]-propan-1-one (NS7051) attenuates nociceptive transmission in animal models of experimental pain; a pharmacological comparison with the combined $\mu$-opioid receptor agonist and monoamine reuptake inhibitor tramadol. Neuropharmacology. 2008;54(2):331-43.

12. Nelson EM, Philbrick AM. Avoiding Serotonin Syndrome: The nature of the interaction between tramadol and selective serotonin reuptake inhibitors. Annals of Pharmacotherapeutics. 2012;46(12):17126.

13. Rojas-Corrales MO, Gibert-Rahola J, Micó JA. Tramadol induces antidepressant-type effects in mice. Life Sciences. 1998;63(12):175-80.

14. Rojas-Corrales MO, Berrocoso E, Gibert-Rahola J, Micó JA. Antidepressant-like effects of tramadol and other central analgesics with activity on monoamines reuptake, in helpless rats. Life Sciences. 2002;72(2):143-52.

15. Driessen B, Reimann W, Giertz H. Effects of the central analgesic tramadol on the uptake and release of noradrenalin and dopamine in vitro. Br J Pharmacol. 1993;108(3):806-11.

16. Desmeules JA, Pigue, V, Collart L, Dayer P. Contribution of monoaminergic modulation to the analgesic effect of tramadol. Br J Clin Pharmacol. 1996;41(1):7-12.

17. Grond S, Sablotzki A. Clinical pharmacology of tramadol. Clinical Pharmacokinetics. 2004;43(13):879-923.

18. Liu ZM, Zhou WH, Lian Z, Mu Y, Ren ZH, Cao JQ, et al. Drug dependence and abuse potential of tramadol. Acta Pharmacol Sin. 1999;20(1):52-4.

19. Preston KL, Jasinski DR, Testa M. Abuse potential and pharmacological comparison of tramadol and morphine. Drug and Alcohol Dependence. 1991;27(1):7-17.

20. McQuay HJ. Pre-emptive analgesia: a systematic review of clinical studies. Annals of Medicine. 1995;27(2):249-56.

21. Faron-Górecka A, Kuœmider M, Inan SY, Siwanowicz J, Piwowarczyk T, DziedzickaWasylewska M. Long-term exposure of rats to tramadol alters brain dopamine and $\alpha 1$-adrenoceptor function that may be related to antidepressant potency. Eur J Pharmacol. 2004;501(1-3):103-10.

22. Filip M, Wydra K, Inan SY, Dziedzicka-Wasylews ka M, Przegaliński E. Opioid and monoamine systems mediate the discriminative stimulus of tramadol in rats. Eur J Pharmacol. 2004;498(1-3):143-51.

23. Yalcin I, Aksu F, Bodard S, Chalon S, Belzung C. Antidepressant-like effect of tramadol in the unpredictable chronic mild stress procedure: possible involvement of the noradrenergic system. Behavioral Pharmacology. 2007;18(7):623-31.

24. Gutstein HB, Akil H. Opioid Analgesics. In: Goodman \& Gilman's The Pharmacological Basis of
Therapeutics. New York: McGraw-Hill Publishers; 2006:547.

25. Shipton EA. Tramadol: Present and future. Anaesthesia and lintensive Care. 2000;28(4):363-74.

26. Goeringer KE, Logan BK, Christian GD. Identification of tramadol and its metabolites in blood from drug-related deaths and drug-impaired drivers. J Anal Toxicol. 1997;21(7):529-37.

27. Giusti P, Buriani A, Cima L, Lipartiti M. Effect of acute and chronic tramadol on $[3 \mathrm{H}]-5 \mathrm{HT}$ uptake in rat cortical synaptosomes. $\mathrm{Br} \mathrm{J}$ Pharmacol. 1997; 122(2):302-6.

28. Cotman CW, Matthews DA. Synaptic plasma membranes from rat brain synaptosomes: Isolation and partial characterization. Biochim Biophys Acta. 1971;249(2):380-94.

29. Dodd PR, Hardy JA, Oakley AE, Edwardson JA, Perry EK, Delaunay JP. A rapid method for preparing synaptosomes: Comparison with alternative procedures. Brain Res. 1981;226(1):107-18.

30. Kodavanti PRS, Mundy WR, Tilson HA, Harry GJ. Effects of selected neuroactive chemicals on calcium transporting systems in rat cerebellum and on survival of cerebellar granule cells. Fundam Appl Toxicol. 1993;21(3):308-16.

31. Kari HP, Davidson PP, Herbert HH, Kochhar MH. Effects of ketamine on brain monoamines levels in rats. Research Communications in Chemical Pathology and Pharmacology. 1978;20(3):475-88.

32. Anden NE, Rool BE, Wegdininus B. On the occurrence of HVA in the brain and cerebrospinal fluid and its determination by fluorometric method. Life Sciences 1963;2(7):448-58.

33. Haubrich DR, Denzer JS. Simultaneous extraction and fluorometric measurement of brain serotonin, catecholamine, 5-HIIA and HVA. Anal Biochem. 1973;55(1):306-12.

34. Ansell GB, Beeson MF. A rapid and sensitive procedure for the combined assay of noradrenalin, dopamine and serotonin in single brain sample. Anal Biochem. 1968;23(2):196-206.

35. Dayer P, Collart L, Desmeules J. The pharmacology of tramadol. Drugs. 1994;47:3-7.

36. Frink MC, Hennies HH, Englberger W, Haurand M, Wilffert B. Influence of tramadol on neurotransmitter systems of the rat brain. Arzneim Forsch. 1996;46(11):1029-36.

37. Bloms-Funke P, Dremencov E, Cremers TIFH, Tzschentke TM. Tramadol increases extracellular levels of serotonin and noradrenalin as measured by in vivo microdialysis in the ventral hippocampus of freely-moving rats. Neurosci Lett. 2011;490(3):191-5.

38. Bosse KE, Maina FK, Birbeck JA, France MM, Roberts JJ, Colombo ML, et al. Aberrant striatal dopamine transmitter dynamics in brain-derived neurotrophic factor-deficient mice. $\mathrm{J}$ Neurochem. 2011;120(3):385-95.

39. Kharkevich DA, Churukanov VV. Pharmacological regulation of descending cortical control of the 
nociceptive processing. Eur J Pharmacol. 1999;375(1):121-31.

40. Hoyer D, Clarke DE, Fozard JR, Hartig PR, Martin GR, Mylecharane EJ. International union of pharmacology classification of receptors for 5hydroxytryptamine (serotonin). Pharmacol Rev. 1994;46(2):157-203.

41. Benson GJ. Physiologic effects of pharmacological agents. Veterinary Clinical Services, Anesthesia and Analgesia. Yale Animal Resource Center, 2005.

42. Di Chiara G, Imperato A. Drugs abused by humans preferentially increase synaptic dopamine concentrations in the mesolimbic system of freely moving rats. Proc Natl Acad Sci USA. 1988;85(14):5274-8.

43. Shyr MH, Tsai TH, Yang CH, Chen HM, Ng HF, Tan PPC. Propofol anesthesia increases dopamine and serotonin activities at the somato-sensory cortex in rats: A microdialysis study. Anesthesia and Analgesia. 1997;84(6): 1344-8.

44. Honkanen A, Hyytiä P, Korpi EE, Ahtee L. Effects of morphine on metabolis $m$ of dopamine and serotonin in brains of alcohol-preferring AA and alcohol-avoiding ANA rats. Alcohol. 1999;18(1):3-10.

45. Yoshida Y, Koide S, Hirose N, Takada K, Tomiyama K, Koshikawa N, et al. Fentanyl increases dopamine release in rat nucleus accumbens: involvement of mesolimbic mu- and delta-2-opioid receptors. Neuroscience. 1999;92(4):1357-65.

46. Sandrini M, Vitale M, Pini LA: Effect of rofecoxib on nociception and the serotonin system in the rat brain. Inflammation Res. 2002;51(3):154-9.

47. Raffa RB, Friderichs E, Reimann W, Shank RP, Codd EE, Vaught JL. Opioid and non-opioid components independently contribute to the mechanism of action of tramadol, an 'atypical' opioid analgesic. J Pharmacol Exp Ther. 1992;260(1):275-85.

Cite this article as: Panadanabiona SC. Alterations in aminergic system of rat brain by the opioid analgesic tramadol in the absence of pain-induction. Int J Basic Clin Pharmacol 2017;6:2774-82. 